\title{
Post-traumatic growth among gastrointestinal oncological patients: the perspective of Stevan Hobfoll's conservation of resources theory
}

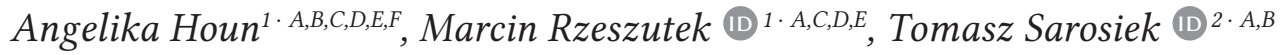 \\ 1: Faculty of Psychology, University of Warsaw, Warsaw, Poland \\ 2: NZOZ Magodent Oncological Hospital Elbląska, Warsaw, Poland
}

BACKGROUND

This study assessed the relation between social support dimensions and post-traumatic growth (PTG) among a sample of gastrointestinal cancer patients. Particular focus was placed on the mediating role of resources based on the conservation of resources (COR) theory and its effect on the previously mentioned association.

\section{PARTICIPANTS AND PROCEDURE}

A total of 190 patients comprising 87 females and 103 males with a clinical diagnosis of gastrointestinal cancer were recruited to participate in this study. This was a crosssectional study, with social support evaluated by the Berlin Social Support Scales (BSSS). The participants' levels of subjectively possessed resources were assessed by the Conservation of Resources Evaluation (COR-E) questionnaire. Posttraumatic growth was evaluated by the PostTraumatic Growth Inventory (PTGI).
RESULTS

No direct relation was found between social support and PTG among participants. However, a mediating role of subjectively possessed resources was detected through the COR theory on the aforementioned relationship, i.e. the link between social support and PTG. More specifically, the level of economic and political resources was a mediator in the relation.

\section{CONCLUSIONS}

These results contribute to extant literature on the psychological aspects of gastrointestinal cancer. Evidently, social support may be related to positive outcomes among gastrointestinal cancer patients in the form of PTG.

\section{KEY WORDS}

gastrointestinal cancer; social support; conservation of resources (COR) theory; post-traumatic growth

CORRESPONDING AUthor - Angelika Houn, Faculty of Psychology, University of Warsaw, 5/7 Stawki Str., 00-183 Warsaw,

Poland, e-mail: a.houn@student.uw.edu.pl

AUthors' CONTRIBUtion - A: Study design - B: Data collection - C: Statistical analysis - D: Data interpretation .

E: Manuscript preparation · F: Literature search · G: Funds collection

to Cite this ARTICLE - Houn, A., Rzeszutek, M., \& Sarosiek, T. (2020). Post-traumatic growth among gastrointestinal

oncological patients: the perspective of Stevan Hobfoll's conservation of resources theory. Current Issues in

Personality Psychology, 8(1), 41-51.

RECEIVED 10.11.2019 • REVIEWED 29.02.2020 • ACCEPTED 10.03.2020 • PUBLISHED 31.03.2020 


\section{BACKGROUND}

Cancer is a chronic, debilitating disease during which patients often struggle not only with the physical illness, but also with restrictions and emotional states that can elicit depression, increased anxiety, and post-traumatic stress disorder (PTSD) (Akechi et al., 2004; Stark \& House, 2000). Dysfunctions at the somatic level can present themselves as fatigue, pain, insomnia and nausea, among other effects (Teunissen et al., 2007). Isolation and loss of personal relationships may affect a patient's social domain (Weis, 2003). Stress is among many factors associated with a cancer diagnosis and may facilitate feelings of helplessness and hopelessness (Vitek, Rosenzweig, \& Stollings, 2007; Moreno-Smith, Lutgendorf, \& Sood, 2010). Such distress may lead to a decrease in quality of life and can be experienced during any period of the post-diagnosis cancer process (Vitek et al., 2007). Negative feelings may cause cancer patients to avoid seeking treatment, stray from treatment regimens or engage in risky behaviors, which could lead to premature death (Segerstrom \& Miller, 2004). Gastrointestinal cancer is one of the more common forms of cancer, yet its effects on patients' daily functioning have not been studied to a large extent.

The traditional psychological outlook on cancer often focuses on negative aspects associated with the disease, but more recently, a shift in focus has occurred toward the positive aspects, including posttraumatic growth (PTG), which is a "positive psychological change experienced as a result of the struggle with highly challenging life circumstances", as defined by Tedeschi and Calhoun (2004, p. 1). The struggle after trauma may elicit improvements in multiple areas of a person's life, and based on numerous studies, growth has been classified into five domains: appreciation of life, spiritual change, personal strength, new possibilities and relating to others (Tedeschi \& Calhoun, 1996). According to the authors (1996, 2004), social support acts as a catalyst in the growth process for an individual who has experienced a traumatic event, as it allows the person to express negative emotions, which may facilitate cognitive processing and aid in recovery after trauma. In addition, the cognitive process is involved in rumination, along with re-evaluation and redefinition of beliefs or goals, which consequently may help the individual find meaning in the traumatic event and eventually experience growth (Tedeschi \& Calhoun, 1996, 2004). Social support has been identified as a growth-promoting factor among cancer survivors that includes participating in support groups and cultivating supportive personal relationships, providing a sense of understanding and a form of communication for survivors (Connerty \& Knott, 2013; Schwarzer, Luszczynska, Boehmer, Taubert, \& Knoll, 2006). PTG was found to be directly related to various health benefits in many samples (Kim, Kim, \& Park, 2016), including cancer patients (Casellas-Grau, Ochoa, \& Ruini, 2017). Particularly with cancer patients, existential dimensions such as meaning-making processes seem to be linked with PTG (Park, Edmondson, Fenster, \& Blank, 2008). Bellizzi and Blank (2006) found that among individuals suffering from cancer, the higher the degree of threat to a patient's health and life, the more positive the PTG changes.

Distress is highly prevalent among cancer patients; thus, an increased ability to cope with stress effectively is essential (Mehnert et al., 2017). Most studies on cancer patients have focused on the transactional model of stress and coping, introduced by Lazurus and Folkman (1984; e.g. Lambert, Yoon, Ellis, \& Northouse, 2015; Paterson, Robertson, \& Nabi, 2015). However, the theory is based on subjective perceptions as a criterion factored into determining whether stress is being experienced or not, thus making it difficult to falsify (Heszen-Niejodek, 2013). Most studies only use parts of the model, and even then, the research is vague (Skinner, Edge, Altman, \& Sherwood, 2003). Moreover, as mentioned above, a cancer diagnosis brings numerous, often negative, changes in various areas of a patient's life. Following that, the distress experienced by cancer patients may also be connected with the depletion of different resources, as proposed by Hobfoll's conservation of resources (COR) theory (Hobfoll, 2001). Therefore, this study took a different approach by using Hobfoll's COR theory. This theory differs from Lazarus and Folkman's theory (1984) mainly in that the former's main focus is on resources, while the latter focuses on cognitive appraisal. According to Hobfoll (2002), psychological stress occurs when the threat of a loss of resources exists, an actual loss of resources occurs or a lack of gained resources exists after a loss of resources. The author defines resources as something that an individual values, particularly objects, states and conditions. Following the COR theory, in that a reduction in resources may affect mental health negatively, it has been shown that during the immediate period after diagnosis, higher anxiety levels are associated with continuous distress symptoms caused solely by the depletive effect on positive affect (Hou, Law, \& Fu, 2010). In the same study, increased symptom distress was linked to higher anxiety and depressed mood compared with patients who reported stable symptom distress. Some of the latest studies also highlighted the role of COR resources in coping with the diseases, especially by dealing with illness-related pain (Pięta, Rzeszutek, \& Gasik, 2019). Furthermore, resource loss may hinder coping strategies; hence, halting or slowing down the process of losing resources can be linked to positive results in terms of traumatic stress (Hall, Rattigan, Walter, \& Hobfoll, 2006). Positive changes, such as PTG, may follow after the experience of a stressful event in that the individual reevaluates interpersonal 
relations and the perception of oneself and the world. Research regarding the role of resources (as proposed by the COR theory) and PTG in the context of cancer seems to be lacking. Therefore, this paper hopes to fill the existing research gaps.

\section{CURRENT STUDY}

This study's objective was to examine the association between social support dimensions (perceived, received and provided) and post-traumatic growth among a sample of gastrointestinal cancer patients. In particular, we wanted to verify the mediating role of resources, as described by the COR theory, in the aforementioned relationship while controlling for selected socio-medical data. We formulated two hypotheses:

H1. A direct, positive relationship exists between levels of perceived, received and provided support and PTG intensity among participants.

H2. The relationship between levels of perceived, received and provided support and PTG intensity is mediated partially by levels of resources from COR theory.

\section{PARTICIPANTS AND PROCEDURE}

\section{PARTICIPANTS}

The present study concerned a sample of 190 adults with a clinical diagnosis of gastrointestinal cancer. The patients were recruited from Warsaw's Non-Public Health Care Facility Magodent Oncological Hospital, Clinical Department of Oncology and Haematology at the Central Clinical Hospital of the Ministry of Interior and Administration, and the Oncology Clinic at the Military Institute of Medicine. One of the authors who was responsible for data collection approached individuals at the aforementioned hospitals who were 18 or older with a clinical diagnosis of gastrointestinal cancer and asked them to voluntarily fill out a set of paper-and-pencil questionnaires. Participants were given an hour to complete the questionnaires and then they were collected by the author. This research project was approved by the ethics committee. Table 1 presents the study sample's socio-medical characteristics.

\section{MEASURES}

Berlin Social Support Scales. To assess social support in light of the participants' cancer diagnosis, an adapted Polish version (Łuszczyńska, Kowalska, Mazurkiewicz, \& Schwarzer, 2006) of Schulz and Schwarzer's (2003) Berlin Social Support Scales (BSSS) was
Table 1

Socio-medical variables in the studied sample $(N=190)$

\begin{tabular}{lc}
\hline Variable & $n(\%)$ \\
\hline Gender & \\
$\quad$ Male & $103(54.21)$ \\
$\quad$ Female & $87(45.79)$ \\
Age in years $(M \pm S D)$ & $63.43 \pm 10.89$ \\
Marital status & \\
$\quad$ Married & $151(79.47)$ \\
$\quad$ Single & $39(20.53)$
\end{tabular}

Education

Elementary

Secondary

Higher education

Employment

Full employment

Unemployed

Illness allowance

Retired

Place of residence

Village, small town up to 20 thousand residents

City 21 to 100 thousand residents

City 101 to 500 thousand residents

City over 500 thousand residents

Lack of permanent residence

Years of diagnosis $(M \pm S D)$

Chemotherapy

Yes

No

Metastasis

Yes

$110(57.89)$

No

$80(42.11)$

used. This particular study utilized three social support scales: perceived available support, actually received support and provided support. The BSSS contain statements about social support from multiple sources, such as family, friends, or colleagues, and requires participants to specify to what extent 
a given statement reflects the individual's beliefs using a Likert scale ranging from 1 (completely untrue) to 4 (completely true). The adapted Polish version of the BSSS has been used with various groups of patients, including those who have undergone bypass operations, experienced heart attacks or have been diagnosed with chronic degenerative spinal disease (Łuszczyńska et al., 2006). Results from these studies have confirmed satisfactory reliability and validity.

Conservation of Resources Evaluation. A Polish adaptation of Conservation of Resources Evaluation (COR-E) by Dudek, Gruszczyńska, and Koniarek (2006) was used to assess the level of subjectively possessed resources among the gastrointestinal cancer patients, regarding their cancer diagnosis. This study used the short version, which includes 40 items from the following resource categories: vital, spiritual, family, economic, political, and power and prestige. COR-E comprises two parts: In Part A, participants rate the importance of the aforementioned resource categories on a Likert scale ranging from 1 (not important) to 5 (very important). In Part B, participants rate the same categories as in Part A, but instead report to what extent each resource characterizes the individual at the given time. This part also uses a Likert scale, ranging from 0 ( $I$ do not possess this particular resource at all) to 5 (I possess this particular resource to a large extent). The levels of particular resource subgroups, in addition to the global resource indicator, were obtained by multiplying the resources' importance ratings by the given resources' current levels of possession.

Post-Traumatic Growth Inventory. Finally, PTG level was evaluated through Ogińska-Bulik and Juczyński's (2010) Polish adaptation of Tedeschi \& Calhoun's (1996) Post-Traumatic Growth Inventory (PTGI). The Polish adaptation of the PTGI comprised four PTG domains (changes in self-perception, changes in relationships with others, greater appreciation of life and spiritual changes), while the original PTGI includes five PTG domains (relating to others, new possibilities, personal strength, spiritual change and appreciation of life). The questionnaire asks participants to rate 21 positive statements that describe various changes after traumatic or highly challenging events mentioned at the beginning of the questionnaire. Participants were asked to focus solely on their gastrointestinal cancer diagnosis as a highly stressful event that then could be related to positive changes regarding PTG. According to Ogińska-Bulik and Juczyński (2010), the statistical analysis usually is performed solely to obtain a global PTG score (sum of all items), as the particular subscales in the Polish version of the PTGI are highly intercorrelated. Furthermore, some authors also recommend a unifactorial assessment of PTG (Park \& Helgeson, 2006). The recommendations were considered during data analysis in this study.

\section{DATA ANALYSIS}

The introductory portion of this study's statistical analysis comprised descriptive statistics and Pearson's correlation coefficients between the analyzed variables. The principal part of the analysis was performed with PROCESS macro software and based on Model No. 4, which allows for testing multiple mediators, one explaining variable and one explained variable. First, the general resource level was tested in the role of a partial mediator. The next model comprised four parallel mediators: spiritual, hedonistic and vital, family, and economic and political resources, with three explaining variables - perceived, received and provided support - which were tested in three different mediation models. The explained variable in each model was PTG level. The mediation effects were verified through a test based on bootstrap sampling, with the number of bootstrap samples equal to 5,000. A statistically significant total effect of the relationship between social support and PTG level was not considered an indispensable condition for detection of mediation, because opposing mediational processes can conceal the relationship between explaining and explained variables and the test of the mediated effect has more statistical power than the test of the overall relation of the two (MacKinnon, 2008).

\section{RESULTS}

Table 2 presents descriptive statistics for all analyzed interval variables, including mean values, standard deviations, skewness, kurtosis and Cronbach's $\alpha$ reliability coefficients.

Skewness and kurtosis values fell between -1 and 1 , so the use of parametric statistical methods was appropriate. Pearson's correlation coefficients revealed positive relationships between perceived, received and provided support and levels of all COR resources, and also between all COR resources and post-traumatic growth.

Table 3 presents the values of COR resources, support and PTG in the group of participants undergoing chemotherapy and in the group of participants not undergoing chemotherapy and also in the group of participants with metastasis and in the group of participants without metastasis with the values of independent samples Student's $t$-test. General level of resources, levels of hedonistic and vital resources, spiritual resources, economic and political resources and power and prestige resources were significantly higher in the group of participants undergoing chemotherapy than in the group of participants not undergoing chemotherapy. There were no statistically significant differences between the group of participants with metastasis and the group of participants without metastasis. 


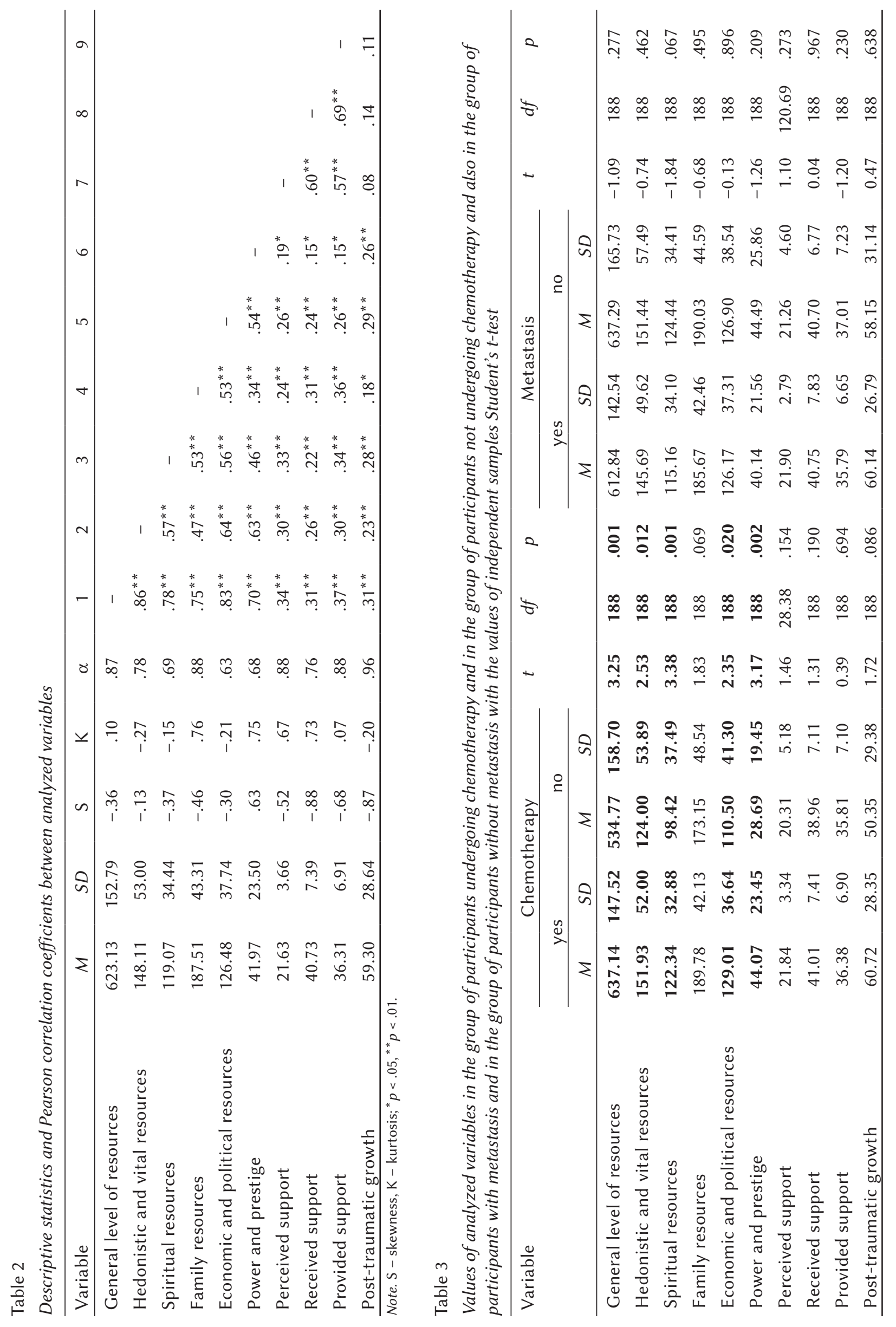


To verify the formulated hypothesis, regression coefficients computed with the macro Process in the mediation models were used (Hayes, 2013). In the total effect model, the relationships between PTG and received, perceived and provided support were statistically insignificant (see Table 4), so the results did not confirm the $\mathrm{H} 1$ hypothesis.

The model concerned with perceived support and the general resource level performed statistical control over not being in a stable relationship, $\mathrm{B}=-50.56$, $t=-2.00, p<.05$, and not undergoing chemotherapy, $\mathrm{B}=-83.24, t=-2.77, p<.05$. Both not being in a stable relationship and not undergoing chemotherapy were related to a lower general level of resources.

The model concerned with perceived support and the specific resource level performed statistical control over not being in a stable relationship and not undergoing chemotherapy. Lack of a stable relationship was related negatively to hedonistic and vital resources, $\mathrm{B}=-20.30, t=-2.27, p<.05$; not undergoing chemotherapy was negatively related to hedonistic and vital resources, $\mathrm{B}=-22.15, t=-2.09, p<.05$, spiritual resources, $\mathrm{B}=-19.64, t=-2.88, p<.01$, and power and prestige resources, $\mathrm{B}=-13.87, t=-2.85$, $p<.01$.

The model concerned with received support and the general level of resources performed statistical control over not undergoing a course of chemotherapy, which was related to a lower general level of resources, $\mathrm{B}=-90.11, t=-2.98, p<.01$.

The model in which received support and level of specific resources were analyzed performed statistical control over not undergoing a course of chemotherapy and not having metastasis. Getting beyond the chemotherapy period was related negatively to hedonistic and vital resources, $\mathrm{B}=-26.84, t=-2.45$, $p<.05$; spiritual resources, $\mathrm{B}=-25.46, t=-3.64$, $p<.001$; economic and vital resources, $\mathrm{B}=-16.99$, $t=-2.16, p<.05$, and power and prestige resources, $\mathrm{B}=-16.30, t=-3.33, p<.01$; and not having metastasis was positively related to spiritual resources, $\mathrm{B}=12.64, t=2.61, p<.01$.

The model concerned with providing support and a general level of resources performed statistical control over not undergoing a course of chemotherapy, related to a lower general level of resources, $\mathrm{B}=-97.73, t=-3.34, p<.01$.

The model in which provided support and the specific resource level were analyzed performed statistical control over undergoing a course of chemotherapy, which was negatively related to hedonistic and vital resources, $\mathrm{B}=-26.64, t=-2.52, p<.05$; spiritual resources, $\mathrm{B}=-22.97, t=-3.44, p<.001$; economic and vital resources, $\mathrm{B}=-17.70, t=-2.32, p<.05$; and power and prestige resources, $\mathrm{B}=-15.09, t=-3.14$, $p<.01$.

To verify the $\mathrm{H} 2$ hypothesis, mediation analysis was performed. Total perceived, received and provided support was analyzed as explaining variables, the levels of resources as mediators and PTG as explained variables, but total resource levels were analyzed in a separate model, not together with the specific types of resources. Figure 1 presents the assumed relationships between analyzed variables.

Three types of paths were analyzed. The 'a' path, between the explaining variable and the mediator; the ' $b$ ' path, between the mediator and the explained variable; and the 'c' path, between the explaining and explained variables, total (c) and direct (c'), with statistical controls over the mediators.

Table 4 presents acquired-regression coefficients in the mediation analysis, along with the values of

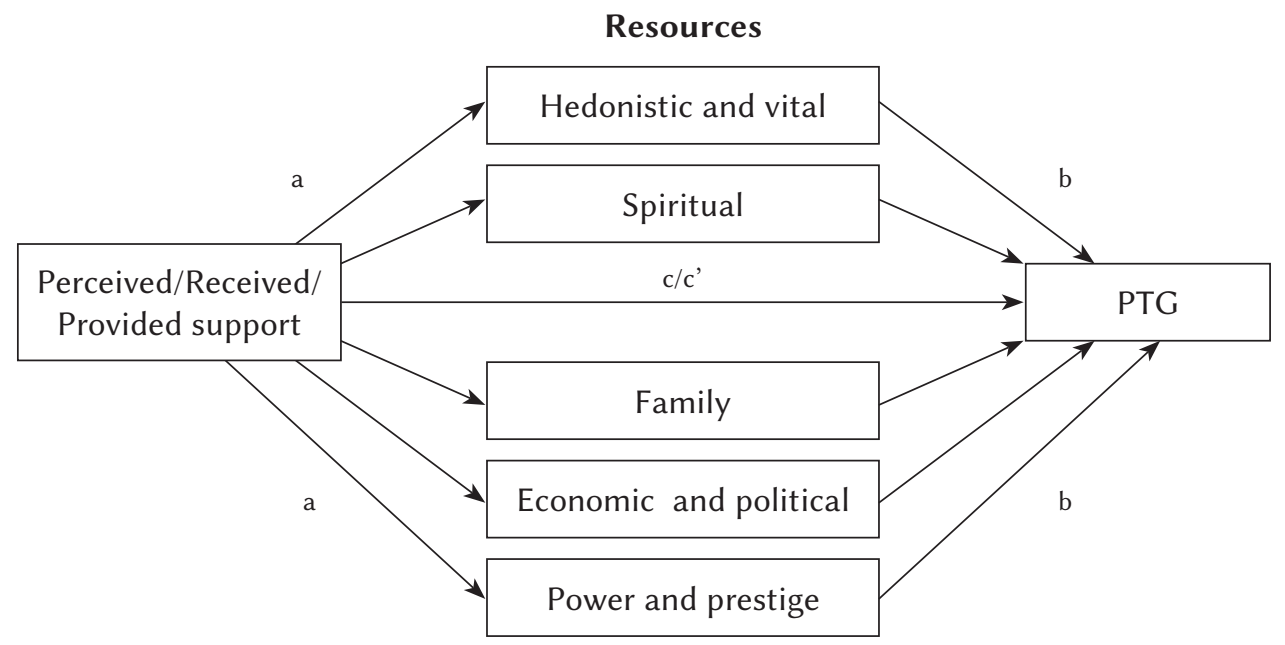

Total level of resources

Figure 1. Hypothesized relationships among analyzed variables. 


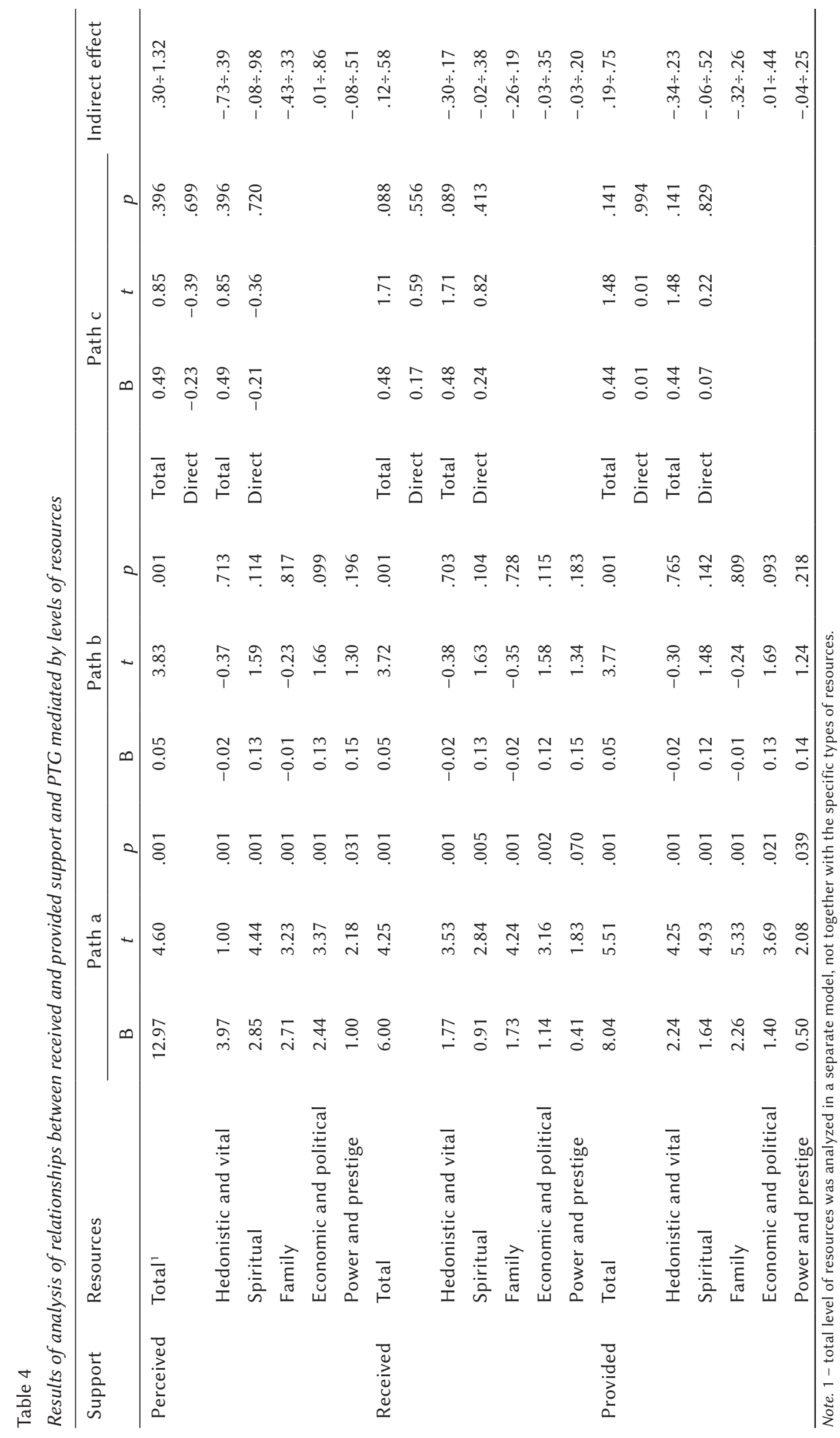


statistical tests for mediation effects based on bootstrap sampling. The total level of resources was a statistically significant mediator of the relationship between perceived, received and provided support and PTG. In each instance, the higher level of support was related to a higher total resource level, which, in turn, was related to a higher PTG level.

Analyzing specific types of resources led to a better understanding of the mediation process. The level of economic and political resources was the mediator of the relationship between perceived support and PTG and between provided support and PTG. Higher levels of perceived support and provided support were related to higher total levels of economic and political resources, which, in turn, were related to higher PTG levels.

\section{DISCUSSION}

The results of this study did not confirm the first hypothesis, as the level of perceived, received or provided support was not directly related to PTG intensity in gastrointestinal cancer patients. This is reflected in a study conducted by Sears, Stanton, and Danoff-Burg (2003), who were unable to find a direct relation between PTG and social support among cancer patients. This study did not discriminate against the various stages of diagnosis, which could explain why a direct relation was not found between social support and levels of PTG. It is possible that some participants simply did not have enough time to experience PTG. According to Morris, Shakespeare-Finch, and Scott (2007), women tend to experience significantly higher levels of PTG than men; thus the relation between social support and PTG may have been influenced by the fact that this sample of participants included more men than women. In contrast, other studies suggest that social support may facilitate PTG, as it includes interpersonal interactions that help individuals reach positive outcomes (Bianco \& Eklund, 2001). For example, in a study among breast cancer survivors, the results showed that sharing thoughts with others about the breast cancer experience was associated with greater PTG levels (Cordova, Cunningham, Carlson, \& Andrykowski, 2001). Social support was identified as a growth-promoting factor among cancer survivors (Connerty \& Knott, 2013), one that included participating in support groups and having supportive personal relationships to provide survivors with a sense of understanding and a form of communication. However, the literature on PTG and social support in cancer patients has barely considered the role of resources in terms of COR theory (Hobfoll, 2001), and according to this study's results, these resources play a distinct role in the cancer recovery process.

The second hypothesis was confirmed, as total resource levels significantly mediated the relation- ship between perceived, received and provided support and PTG. In accordance with the COR theory (Hobfoll, 2001, 2002; Hobfoll et al., 2007), resources may be reappraised using two mechanisms: the shift of the focus of attention and the revaluation of resources. Thus, it is possible that support may facilitate the reappraisal and increase of resources which then could lead to experiencing growth. The core of the COR theory is that humans work to protect the resources they already possess and strive to acquire new resources. Benefit finding may be directly affected by received social support (Tedeschi \& Calhoun, 1996) and can also enable coping strategies which in turn would adjust the threat level of stress (Bandura, 1997). When one receives social support, it may help the individual activate various coping strategies and decrease the threat level of stress, which could lead to an improved ability to gather or retain resources and consequently facilitate growth (Chen, Westman, \& Eden, 2009; Diestel \& Schmidt, 2012). In this case, by receiving social support, the cancer patients could potentially change their perception of the threat of their illness, experience less stress as a result and in turn be able to increase their general resource levels, hence improving their chances of experiencing PTG.

This study also found that economic and political resources, in particular, were statistically significant mediators of the relationship between perceived support and PTG, as well as providing support and PTG. This could be explained by the possibility that patients with higher income levels are able to devote more time and energy to treatment, as they have a lighter financial burden (Hamel et al., 2017). Moreover, these patients would be more likely to be able to afford expensive drugs and treatment, which could facilitate PTG. A higher education level could indicate that a patient can process problems from a more comprehensive perspective. Patients with higher education levels tend to provide rather optimistic explanations for negative life events and report higher levels of PTG, while higher household income can also influence the development of PTG, which can be associated positively with education level (Ho, Chan, \& Ho, 2011; Wang, Liu, Wang, Chen, \& Li, 2014). Other studies have reported similar results (Cordova et al., 2007; Koutrouli, Anagnostopoulos, \& Potamianos, 2012).

\section{STRENGTHS AND LIMITATIONS}

A major strength of this study, which is theory-based, is that it is the first to explore the relation between PTG and social support among gastrointestinal cancer patients using the COR theory perspective. Nevertheless, it is important to note a few limitations related to the study. First, the study's cross-sectional design hindered causal interpretation of the results, particularly the assessment of participants' resource 
loss or gain over a longer period of time. Next, few medical variables were controlled among the participants. Finally, the study sample was heterogeneous in terms of gastrointestinal cancer diagnosis type, cancer diagnosis stage, disease duration and treatment, and metastasis. Future studies should consider a more homogeneous sample.

\section{CONCLUSIONS}

Regardless of the study's limitations, the results facilitated a better understanding of the psychological aspects related to gastrointestinal cancer while also contributing to extant literature on the relation between PTG and social support under the COR framework. Evidently, social support dimensions appear to be related to positive outcomes among gastrointestinal cancer patients in the form of PTG.

\section{REFERENCES}

Akechi, T., Okuyama, T., Sugawara, Y., Nakano, T., Shima, Y., \& Uchitomi, Y. (2004). Major depression, adjustment disorders, and post-traumatic stress disorder in terminally ill cancer patients: associated and predictive factors. Journal of Clinical Oncology, 22, 1957-1965. https://doi.org/10.1200/JCO.2004.08.149

Bandura, A. (1997). Self-efficacy: The exercise of control. New York, NY: Freeman.

Bellizzi, K. M., \& Blank, T. O. (2006). Predicting posttraumatic growth in breast cancer survivors. Health Psychology, 25, 47-56. https://doi.org/10.1037/02786133.25.1.47

Bianco, T., \& Eklund, R. C. (2001). Conceptual considerations for social support research in sport and exercise settings: The case of sport injury. Journal of Sport and Exercise Psychology, 23, 85-107.

Casellas-Grau, A., Ochoa, C., \& Ruini, C. (2017). Psychological and clinical correlates of posttraumatic growth in cancer: a systematic and critical review. Psycho-Oncology, 26, 2007-2018. https://doi. org/10.1002/pon.4426

Chen, S., Westman, M., \& Eden, D. (2009). Impact of enhanced resources on anticipatory stress and adjustment to new information technology: a fieldexperimental test of conservation of resources theory. Journal of Occupational Health Psychology, 14, 219-230. https://doi.org/10.1037/a0015282

Connerty, T., \& Knott, V. (2013). Promoting positive change in the face of adversity: Experiences of cancer and post-traumatic growth. European Journal of Cancer Care, 22, 334-344. https://doi.org/10.1111/ ecc. 12036

Cordova, M. J., Cunningham, L. L., Carlson, C. R., \& Andrykowski, M. A. (2001). Posttraumatic growth following breast cancer: a controlled comparison study. Health Psychology, 20, 176-185. https://doi. org/10.1037/0278-6133.20.3.176

Cordova, M. J., Giese-Davis, J., Golant, M., Kronenwetter, C., Chang, V., \& Spiegel, D. (2007). Breast cancer as trauma: posttraumatic stress and posttraumatic growth. Journal of Clinical Psychology in Medical Settings, 14, 308-319. https://doi.org/10.1007/ s10880-007-9083-6

Diestel, S., \& Schmidt, K. (2012). Lagged mediator effects of self-control demands on psychological strain and absenteeism. Journal of Occupational and Organizational Psychology, 85, 556-578. https://doi.org/10.1111/j.2044-8325.2012.02058.x

Dudek, B., Gruszczyńska, E., \& Koniarek, J. (2006). Teoria zachowania zasobów S. Hobfolla - zagadnienia teoretyczne i metodologiczne oraz adaptacja kwestionariusza COR-Evaluation [Conservation of resources theory by $\mathrm{S}$. Hobfoll - theoretical and methodological issues and adaptation of the COR-Evaluation questionnaire]. In T. Pasikowski \& H. Sęk (Eds.), Psychologia zdrowia: teoria, metodologia i empiria [Health psychology: theory, methodology and empiricism] (pp. 51-60). Poznań: Bogucki Wydawnictwo Naukowe.

Hall, B. J., Rattigan, S., Walter, K. H., \& Hobfoll, S. E. (2006). Conservation of resources theory and trauma: an evaluation of new and existing principles. In P. Buchwald (Ed.), Stress and anxiety - application to health, community, work place, and education (pp. 230-250). Newcastle: Cambridge Scholar Press.

Hamel, L. M., Penner, L. A., Eggly, S., Chapman, R., Klamerus, J. F., Simon, M., Stanton, S. C., \& Albrecht, T. L. (2017). Do patients and oncologists discuss the cost of cancer treatment? An observational study of clinical interactions between African American patients and their oncologists. Journal of Oncology Practice, 13, e249-e258. https:// doi.org/10.1200/JOP.2016.015859

Hayes, A. F. (2013). Introduction to mediation, moderation, and conditional process analysis: a regression-based approach. New York: Guilford Press.

Heszen-Niejodek, I. (2013). Psychologia stresu: korzystne i niekorzystne skutki stresu życiowego [Psychology of stress: the beneficial and adverse effects of life stress]. Warszawa: Wydawnictwo Naukowe PWN.

Ho, S. M., Chan, C. L., \& Ho, R. T. (2011). Posttraumatic growth in Chinese cancer survivors. Psycho-Oncology, 13, 377-389. https://doi.org/10.1002/pon.758

Hobfoll, S. E. (2001). The influence of culture, community, and the nested-self in the stress process: Advancing conservation of resources theory. Applied Psychology, 50, 337-421. https://doi.org/ 10.1111/1464-0597.00062

Hobfoll, S. E. (2002). Social and psychological resources and adaptation. Review of General Psychology, 6, 307-324. https://doi.org/10.1037/1089-2680.6.4.307

Hobfoll, S. E., Hall, B. J., Canetti-Nisim, D., Galea, S., Johnson, R. J., \& Palmieri, P. A. (2007). Refining our 
understanding of traumatic growth in the face of terrorism: Moving from meaning cognitions to doing what is meaningful. Applied Psychology, 56, 345366. https://doi.org/10.1111/j.1464-0597.2007.00292.x

Hou, W. K., Law, C. C., \& Fu, Y. T. (2010). Does change in positive affect mediate and/or moderate the impact of symptom distress on psychological adjustment after cancer diagnosis? A prospective analysis. Psychology \& Health, 25, 417-431. https://doi.org/10.1080/08870440802559375

Kim, J., Kim, M., \& Park, S. (2016). Exploring the relationship among posttraumatic growth, life satisfaction, and happiness among Korean individuals with physical disabilities. Psychological Reports, 119, 312-327. https://doi.org/10.1177/0033294116653954

Koutrouli, N., Anagnostopoulos, F., \& Potamianos, G. (2012). Posttraumatic stress disorder and posttraumatic growth in breast cancer patients: a systematic review. Women \& Health, 52, 503516. https://doi.org/10.1080/03630242.2012.679337

Lambert, S. D., Yoon, H., Ellis, K. R., \& Northouse, L. (2015). Measuring appraisal during advanced cancer: Psychometric testing of the appraisal of caregiving scale. Patient Education and Counseling, 98, 633-639. https://doi.org/10.1016/j.pec.2015.01.009

Lazarus, R., \& Folkman, S. (1984). Stress, appraisal, and coping. New York, NY: Springer Publishing Company.

Łuszczyńska, A., Kowalska, M., Mazurkiewicz, M., \& Schwarzer, R. (2006). Berlińskie skale wsparcia społecznego (BSSS): Wyniki wstępnych badań nad adaptacją skal i ich własnościami psychometrycznymi [Berlin social support scales (BSSS): Polish version of BSSS and preliminary results on its psychometric properties]. Studia Psychologiczne, 44, 17-27.

MacKinnon, D. P. (2008). Introduction to statistical mediation analysis. New York, NY: Taylor \& Francis Group.

Mehnert A., Hartung, T. J., Friedrich, M., Vehling, S., Brahler, E., Harter, M., Keller, M., Schulz, H., Wegscheider, K., Weis, J., Koch, U., \& Faller, H. (2017). One in two cancer patients is significantly distressed: Prevalence and indicators of distress. Psycho-Oncology, 27, 75-82. https://doi.org/ 10.1002/ pon. 4464 .

Moreno-Smith, M., Lutgendorf, S. K., \& Sood, A. K. (2010). Impact of stress on cancer metastasis. Future Oncology, 6, 1863-1881. https://doi.org/10.2217/ fon. 10.142

Morris, B. A., Shakespeare-Finch, J., \& Scott, J. (2007). Coping processes and dimensions of posttraumatic growth. The Australian Journal of Disaster and Trauma Studies, 1, 1-11.

Ogińska-Bulik, N., \& Juczyński, Z. (2010). Rozwój potraumatyczny - charakterystyka i pomiar [Posttraumatic growth - characteristic and measurement]. Psychiatria, 7, 129-142.
Park, C. L., Edmondson, D., Fenster, J. R., \& Blank, T. (2008). Meaning making and psychological adjustment following cancer: The mediating roles of growth, life meaning, and restored just-world beliefs. Journal of Consulting and Clinical Psychology, 76, 863-875. https://doi.org/10.1037/a0013348

Park, C. L., \& Helgeson, V. S. (2006). Introduction to the special section: Growth following highly stressful life events - current status and future directions. Journal of Consulting and Clinical Psychology, 74, 791-796. https://doi.org/10.1037/0022-006X.74.5.791

Paterson, C., Robertson, A., \& Nabi, G. (2015). Exploring prostate cancer survivors' self-management behaviours and examining the mechanism effect that links coping and social support to healthrelated quality of life, anxiety and depression: a prospective longitudinal study. European Journal of Oncology Nursing, 19, 120-128. https://doi. org/10.1016/j.ejon.2014.10.008

Pięta, M., Rzeszutek, M., \& Gasik, R. (2019). Body image, pain and level of resources among arthritis patients: The moderating role of gender. Psychology, Health and Medicine. Advanced online publication. https://doi.org/10.1080/13548506.2019.1668566

Schulz, U., \& Schwarzer, R. (2003). Soziale Unterstützung bei der Krankheitsbewältigung: Die Berliner Social Support Skalen (BSSS) [Social support in coping with illness: The Berlin Social Support Scales (BSSS)]. Diagnostica, 49, 73-82. https://doi. org/10.1026//0012-1924.49.2.73

Schwarzer, R., Luszczynska, A., Boehmer, S., Taubert, S., \& Knoll, N. (2006). Changes in finding benefit after cancer surgery and the prediction of well-being one year later. Social Science \& Medicine, 63, 1614-1624. https://doi.org/10.1016/j.socscimed.2006.04.004

Sears, S. R., Stanton, A. L., \& Danoff-Burg, S. (2003). The yellow brick road and the emerald city: Benefit finding, positive reappraisal coping and posttraumatic growth in women with early-stage breast cancer. Health Psychology, 22, 487-497. https://doi. org/10.1037/0278-6133.22.5.487

Segerstrom, S. C., \& Miller, G.E. (2004). Psychological stress and the human immune system: a metaanalytic study of 30 years of inquiry. Psychological Bulletin, 130, 601-630. https://doi.org/10.1037/00332909.130.4.601

Skinner, E., Edge, K., Altman, J., \& Sherwood, H. (2003). Searching for the structure of coping: a review and critique of category systems for classifying ways of coping. Psychological Bulletin, 129, 216-269. https://doi.org/10.1037/0033-2909.129.2.216

Stark, D. P., \& House, A. (2000). Anxiety in cancer patients. British Journal of Cancer, 83, 1261-1267. https://doi.org/10.1054/ bjoc.2000.1405

Tedeschi, R. G., \& Calhoun, L. G. (1996). The PostTraumatic Growth Inventory: Measuring the positive legacy of trauma. Journal of Traumatic Stress, 9, 455-471. https://doi.org/10.1007/BF02103658 
Tedeschi, R. G., \& Calhoun, L. G. (2004). Posttraumatic growth: Conceptual foundations and empirical evidence. Psychological Inquiry, 15, 1-18. https://doi.org/10.1207/s15327965pli1501_01

Teunissen, S. C., Wesker, W., Kruitwagen, C., de Haes, H. C., Voest, E. E., \& de Graeff, A. (2007). Symptom prevalence in patients with incurable cancer: a systematic review. Journal of Pain and Symptom Management, 34, 94-104. https://doi.org/10.1016/j. jpainsymman.2006.10.015

Vitek, L., Rosenzweig, M. Q., \& Stollings, S. (2007). Distress in patients with cancer: Definition, assessment, and suggested interventions. Clinical Journal of Oncology Nursing, 11, 413-418. https:// doi.org/10.1188/07.CJON.413-418

Wang, M. L., Liu, J. E., Wang, H. Y., Chen, J., \& Li, Y. Y. (2014). Posttraumatic growth and associated socio-demographic and clinical factors in Chinese breast cancer survivors. European Journal of Oncology Nursing, 18, 478-483. https://doi.org/10.1016/j. ejon.2014.04.012

Weis, J. (2003). Support groups for cancer patients. Support Care Cancer, 11, 763-768. https://doi. org/10.1007/s00520-003-0536-7 